\title{
Review of Supercritical Hydrothermal Combustion
}

\author{
Haitao Xu ${ }^{1}$, Shuzhong Wang ${ }^{1, *}$, Mengmeng $\operatorname{Ren}^{1}$, Jianqiao Yang ${ }^{1}$, Chengchao Cui ${ }^{1}$, Yanhui \\ $\mathrm{Li}^{1}$, Jie Zhang ${ }^{2}$
}

${ }^{1}$ Key Laboratory of Thermo-Fluid Science and Engineering of MOE, School of Energy and Power Engineering, Xi' an Jiaotong University, China

${ }^{2}$ State Key Laboratory Base of Eco-hydraulic Engineering in Arid Area, Xi'an University of

Technology, China

\begin{abstract}
Two major points in supercritical hydrothermal combustion were reviewed:(1) The structure of semi-batch reactors or continuous reactors used in different institutes and colleges. These investigations can be used to guide the design of reactors for later scholars and lay the foundation for the industrialization of supercritical hydrothermal combustion. (2) The research status of characterization of hydrothermal flame processes by various scholars. These investigations can be used to guide the process parameters of industrialization of supercritical hydrothermal combustion. The continuous reactor designed in each organization is very sophisticated, which can avoid the two major problems of reaction in the supercritical state: salt precipitation and corrosion. The ignition temperature, extinction temperature, and other characteristics of supercritical hydrothermal combustion studied by scholars are summarized and the laws are basically similar. The removal rate of different organic matters was also summarized under supercritical hydrothermal combustion, and the removal rate of more than $99 \%$ was basically achieved.
\end{abstract}

\section{Introduction}

Supercritical water(SCW) refers to water in the environment where both temperature and pressure are above its critical point $\left(\mathrm{T}>374^{\circ} \mathrm{C}, \mathrm{P}>22.1 \mathrm{MPa}\right)$. Supercritical water has special physical and chemical properties such as high diffusivity, low density, low viscosity, low dielectric constant and small amount of hydrogen bonds. Therefore, a satisfactory reaction environment is provided. Supercritical hydrothermal combustion means (SCHC) that in supercritical water, the fuel above a certain concentration reaches the ignition point, and the fuel is ignited with the phenomenon of "water-fire compatibility". Supercritical hydrothermal combustion was first proposed by Franck[1,2] and his colleagues in 1987. For more than 30 years, the University of Valladolid (Uva), Swiss Federal Institute of Technology Zurich(ETH), Xi'an Jiaotong University (Xjtu), Karlsruhe Institute of

*Shuzhong Wang: szwang@aliyun.com 
Technology (KIT) and others research institutes have conducted extensive research on supercritical hydrothermal combustion.

Supercritical hydrothermal combustion is a special supercritical water oxidation process which was firstly proposed by Modell[3], and different scholars gave similar views to judge whether there is severe supercritical water oxidation - supercritical hydrothermal combustion. Provided that the reactor is equipped with a visualization window of sapphire or quartz glass, it can be directly observed whether there are hydrothermal flames in the reactor. The supercritical hydrothermal combustion research results on coal of $\mathrm{Ma}[4]$ represent that when the surface temperature of coal particles is much higher than the temperature of the surrounding fluid (generally the surface temperature of the particles is more than $800{ }^{\circ} \mathrm{C}$ ), it is taken into account that the supercritical hydrothermal combustion reaction of coal occurs. Zhang[5] believes that supercritical hydrothermal combustion occurs when the temperature of fluid in the reactor rises sharply (at least $100{ }^{\circ} \mathrm{C} / \mathrm{min}$ ). Augustine[6] believes that the hydrothermal flame which operates in a regime of thermal runaway has the features of extremely fast reaction rates(with residence times being only $10-100 \mathrm{~ms}$ ) and high temperatures(usually more than $1000^{\circ} \mathrm{C}$ ).

Supercritical hydrothermal combustion has other advantages over flameless supercritical water oxidation. Supercritical hydrothermal combustion can be used to solve two of the major obstacles confronting the practical application of SCWO to the treatment of hazardous, toxic, or non-biodegradable aqueous organic waste streams - metal corrosion at high temperature and plugging of the reactor due to precipitating salt solids[6]. As an example, the temperature in the local high temperature zone possessed by supercritical hydrothermal combustion is higher than that of the flameless supercritical water, so the ability to destroy refractory organic matter is stronger. Additionally, supercritical hydrothermal combustion is more intense than the flameless supercritical water oxidation, and the residence time of supercritical hydrothermal combustion is generally less than $1 \mathrm{~s}$. Moreover, the fast reaction makes the reactor size smaller and the cost less. Therefore, it is easier to industrialize and more economical.

At present, scholars' research on supercritical hydrothermal combustion focuses on flame characteristics: ignition temperature, extinction temperature, flame temperature, flame height (diameter), the total organic carbon (TOC) removal rate of organic matter or waste and the design of the reactor.

\section{Reactor designed by different organization}

Reddy[7] proposed that hydrothermal flames are divided into premixed flames and diffusion limited flames. According to the feed flow rate (usually depends on Reynolds number), hydrothermal flames can also be divided into laminar hydrothermal flames and turbulent hydrothermal flames. The types of hydrothermal flames can be seen in Figure 1. 

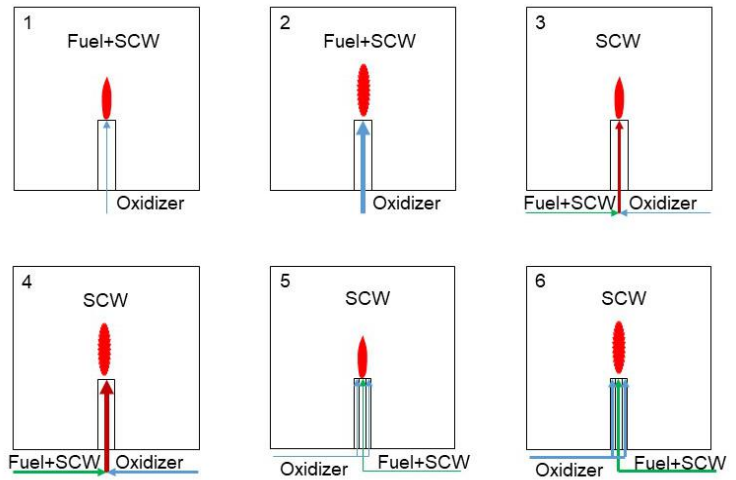

Fig. 1. The types of hydrothermal flames: (1) laminar flames in semi-batch reactor, (2) turbulent flames in semi-batch reactor,(3) laminar flames in continuous reactor(premixed),(4) turbulent flames in continuous reactor(premixed), (5) laminar flames in continuous reactor and (6) turbulent flames in continuous reactor

There are two types of reactors for supercritical hydrothermal combustion: semi-batch reactors and continuous reactors. The semi-batch reactor means that the inside of the reactor is flooded with fuel, and thereafter the oxidant is injected into the reactor through the nozzle, and the fuel is ignited once the inside of the reactor satisfies the hydrothermal flame ignition condition. The flame is extinguished as the internal fuel gradually decreases until it is exhausted. Continuous reactors mean that fuels and oxidants are injected into the interior of the reactor at the same time, and hydrothermal flames are ignited once the inside of the reactor satisfies certain conditions. In theory, the injection of fuel and oxidant is not stopped, and the flame will not be extinguished.

Continuous reactors are divided into three main types: transpiring wall reactor (TWR), wall-cooled hydrothermal burner (WCHB) and tubular reactor. Subcritical water which can form a thin water film is injected into micropores on the inner wall of TWR. The thin water film prevents corrosive substances from coming into contact with the wall and dissolves salts. The wall of the WCHB is cooled with cold water to prevent high-temperature corrosion. The place where the cold water is in contact with the supercritical water can lower the temperature and redissolve the inorganic salt to prevent salt deposition.

\subsection{Semi-batch reactor}

Reactor studies began with semi-batch reactors. The semi-batch reactor used in the Sandia National Laboratory in the United States can be seen in Steeper et al [8]. Steeper uses a $14.7 \mathrm{~mL}$ reactor to prefill water and methane (or methanol) in a supercritical state, and then inject oxygen from the bottom import. Thereby, the process of the hydrothermal flame from ignition to extinction is obtained, and the ignition characteristic curve of methane and methanol is obtained. The device has three sapphire windows, with the right side being the incident laser port, the left side being the transmitted laser port, and the top being the scattered light collection port. The device can therefore identify the indoor components as well as the fuel concentration by using Raman scattering.

The semi-batch reactor used at McGill University can be seen in sobhy et al [9], with a reactor's volume of $15 \mathrm{~mL}$. Sobhy first injects the methanol solution into the reactor through the test fluid loading port. Once the internal pressure of the reactor reaches $23 \mathrm{MPa}$, it is heated to $400{ }^{\circ} \mathrm{C}$. Afterward, $400{ }^{\circ} \mathrm{C}$ of dry air is injected into the reactor through the air injection nozzle to generate a hydrothermal flame. The hydrothermal flame can be observed through the sapphire window port, or the hydrothermal flame image can be 
obtained by infrared imaging. Sobhy obtained the destruction efficiency of naphthalene under hydrothermal combustion conditions by this device.

\subsection{Continuous reactors}

The Federal Institute of Technology in Zurich, Switzerland, began research on supercritical hydrothermal combustion in 1996. The research team designed a TWR and WCHBs. The WCHBs has four generations[10-12], and first three generations are similar in structure.

The water and fuel of the first generation WCHB[10] are injected from the middle lower port, and oxygen is injected into the burner from the side annular port to ignite, while the subcritical water is injected from the outer ring of the burner to cool the burner wall. The product is discharged from the upper port. This generation has two sapphire window ports at the end of the burner, which can see the process of the hydrothermal flames from ignition to extinction. The second generation is similar in structure to the first generation, but the length of the burner is longer, while the sapphire window port is increased from $20 \mathrm{~mm}$ to $165 \mathrm{~mm}$. In comparison with the first generation, the third generation moved the inlet and burner from below to the top, while the sapphire window ports increased from two to four and the length increased from $20 \mathrm{~mm}$ to $85 \mathrm{~mm}$. The hydrothermal combustion reaction in the combustion chamber can be observed from all directions.

The fourth generation WCHB[12] is a combination of a coaxial and a radial nozzle where the fuel is injected at $30^{\circ}$ with respect to the oxygen flow and produces the turbulent flame. Main volume of the reactor is $5.83 \mathrm{~L}$. In addition, inside the combustion chamber is a heating coil that uses electricity to ignite the hydrothermal flame. This is also the focus of ETH's recent research.

The TWR of the Swiss Federal Institute of Technology in Zurich can be seen in Wellig et al[13]. The fuel is injected from the upper center, and the first oxygen is injected into the burner from the outer ring of the fuel port to ignite. The waste water is injected from the outer ring of the burner, and the second oxygen is injected from the outermost ring to the supply oxygen. The lower part of the reactor is a transpiring with four transpiring wall ports for supplying subcritical water to form a thin water film, which not only prevents salt from depositing on the wall, but also prevents high temperature corrosion substances generated by the reaction from contacting on the wall. In addition, since there are four transpiring wall ports, it is easy to install temperature measurement points. The device can also just preheat wall water, fuel and air, and these substances are less corrosive.

The University of Valladolid designed some reactors. The WCHB which can be seen in Bermejo et al[14] designed by the team has a structure that exchanges heat between the internal high-temperature heat source and material. A salt precipitation chamber below ensures that the mixer is not clogged, while a long reaction chamber passage extends the reaction time. Additionally, it is safe for the reason that pressure shell is far away from reaction chamber at high temperature.

Another WCHB was designed by the University of Valladolid, which can be seen in Cabeza et al[15]. The reactor uses cooling water to cool the wall between internal wall and external wall. Feed flow and air are premixed in internal wall and then react in reaction chamber. The reaction product flows out from bottom. This reactor is characterized by its simple structure.

The University of Valladolid also designed a TWR with a volume of 6.3L, which can be seen in Bermejo et al[16]. The reactor consists of stainless steel and the clean transpiring water circulates around the porous wall to protect the wall from corrosion and salt deposition. Similar to the WCHB mentioned before, the feed flow and air are premixed in static mixer and then react in reaction chamber. The reaction products also flow out from bottom. The characteristics of the reactor is that pressure shell which bears pressure is 
separated from reaction chamber which bears high temperature. Therefore, the structure is safer.

China's Xi'an Jiaotong University began research on supercritical hydrothermal combustion in 2005 and designed a multi-functional supercritical hydrothermal combustion reactor, as shown in the following figure 2 . The reactor has an inner cylinder which can be replaced by transpiring wall or cooled wall. Inside the inner cylinder is a combustion reaction chamber with a fuel inlet, a waste inlet and an oxidant inlet. There are four thermocouples on the upper and lower sides to measure the internal temperature. The outer wall is a pressure-bearing wall, and there are three ports on the wall. If the inner cylinder is a cooled wall, the upper left port is blocked, the water is poured from the lower port, and the upper right port is discharged. If the inner cylinder is a porous transpiring wall, the lower port is blocked, and water is supplied from the upper two ports, which mixed with the liquid inside the burner through the transpiring wall, and then discharged through the bottom outlet.

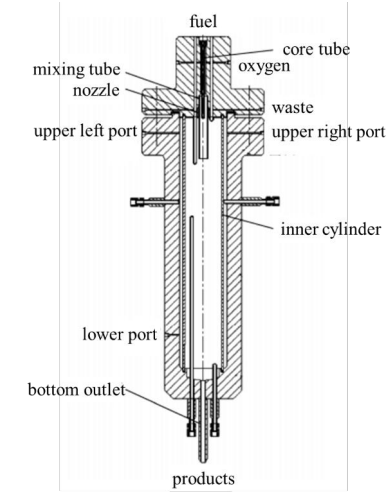

Fig. 2. Xi'an Jiaotong University multi-function reactor[17]

Shandong University also designed a $1.8 \mathrm{~L}$ transpiring wall reactor which can be seen in Zhang et al[5] for hydrothermal combustion experiments. The reactor they designed was similar to the reactor at ETH. Using a retaining ring, the porous wall is divided into two zones, and the transpiring water can pass through the transpiring wall at different temperatures and flow rates. In addition, the fuel, the oxygen and the auxiliary heating fluid were injected from the coaxial nozzle, and therefore the oxidation coefficient and fuel concentration can be changed at any time during the experiment. Zhang used the reactor to test the ignition temperature and the extinction temperature under different flows conditions.

\section{Characterization of hydrothermal flame processes}

\subsection{Ignition temperature}

Ignition temperature is the lowest temperature at which a hydrothermal flame ignites at a certain supercritical pressure and fuel concentration. Some scholars have conducted experimental studies on the relationship between pressure and ignition temperature. As shown in figure 3 and figure 4, Schilling[2] used a semi-batch reactor to measure the ignition temperature of methane at different pressures. The fuel was $30 \mathrm{~mol} \%$ of methane, and the oxidant was pure oxygen. It was found that when the pressure increased from 20 $\mathrm{MPa}$ to $100 \mathrm{MPa}$, the ignition temperature was reduced just from $420^{\circ} \mathrm{C}$ to $400{ }^{\circ} \mathrm{C}$. Steinle[18] also studied the ignition temperature of $30 \mathrm{~mol} \%$ methane in a semi-batch reactor, but he used air as an oxidant and found that when the pressure increased from 32 
$\mathrm{MPa}$ to $100 \mathrm{MPa}$, the ignition temperature decreased from $420^{\circ} \mathrm{C}$ to $395^{\circ} \mathrm{C}$. Hirth[19] used a semi-batch reactor to measure the ignition temperature of different concentrations of methane at different pressures. The fuel was methane and the oxidant was pure oxygen. It was found that the pressure increased from $30 \mathrm{MPa}$ to $100 \mathrm{MPa}$ and $30 \mathrm{~mol} \%$ methane ignition temperature was reduced from $425^{\circ} \mathrm{C}$ to $390^{\circ} \mathrm{C}$. The results of the three scholars had shown that the increase in pressure is conducive to the reduction of the ignition temperature.

The scholars also conducted an experimental study on the relationship between the concentration of fuel and the ignition temperature. Hirth found that if the pressure was unchanged at $60 \mathrm{MPa}$, the methane concentration increased from $10 \mathrm{~mol} \%$ to $30 \mathrm{~mol} \%$, and the ignition temperature was reduced from $500{ }^{\circ} \mathrm{C}$ to $410{ }^{\circ} \mathrm{C}$; if the holding pressure was unchanged at $73 \mathrm{MPa}$, the methane concentration was increased from $5 \mathrm{~mol} \%$ to $20 \mathrm{~mol} \%$, and the ignition temperature decreased from $450{ }^{\circ} \mathrm{C}$ to $350^{\circ} \mathrm{C}$. Steeper[8] studied the ignition characteristics of not only methane, but also methanol. Using pure oxygen as the oxidant, he found in a semi-batch reactor at a reaction pressure of $27.5 \mathrm{MPa}$, when methane was increased from $5 \mathrm{~mol} \%$ to $12 \mathrm{~mol} \%$, the ignition temperature decreased from $480{ }^{\circ} \mathrm{C}$ to $380{ }^{\circ} \mathrm{C}$; when methanol was increased from $6 \mathrm{~mol} \%$ to $36 \mathrm{~mol} \%$, the ignition temperature decreased from $475^{\circ} \mathrm{C}$ to $405^{\circ} \mathrm{C}$. The experimental results of Sobhy[9] showed that under the condition of $23 \mathrm{MPa}$, air as an oxidant, the concentration of methanol increased from $11.2 \mathrm{~mol} \%$ to $32.3 \mathrm{~mol} \%$, and the ignition temperature decreased from $400{ }^{\circ} \mathrm{C}$ to $350{ }^{\circ} \mathrm{C}$. Experiments conducted by Reddy[20] showed that under the pressure of $22.5 \mathrm{MPa}$, air as an oxidant, the concentration of n-propanol increased from $0.7 \mathrm{~mol} \%$ to $1.9 \mathrm{~mol} \%$, and the ignition temperature decreased from $360{ }^{\circ} \mathrm{C}$ to $330{ }^{\circ} \mathrm{C}$. Ren[21] found that the ignition temperature of $8 \mathrm{wt} \%$ quinolone is $425{ }^{\circ} \mathrm{C}$ in a batch reactor and it decreased to $400{ }^{\circ} \mathrm{C}$ when the quinolone increased to $10 \mathrm{wt} \%$. It can be seen that the ignition temperature decreases as the fuel concentration increases, and the ignition temperature of methane is lower than that of methanol. In addition, materials of large molecular weight can be ignited at low molar concentrations.

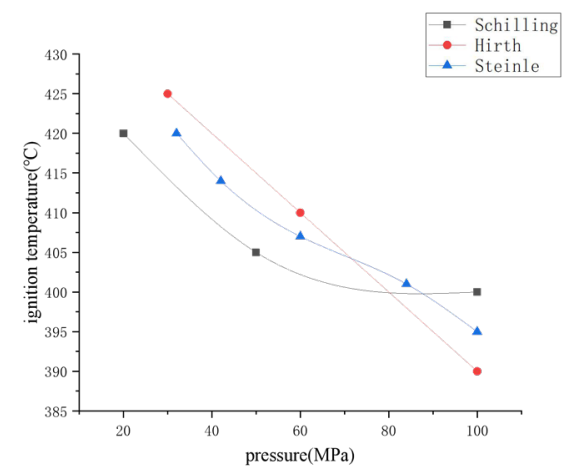

Fig. 3. Relationship between ignition temperature and pressure of $30 \mathrm{~mol} \%$ methane 


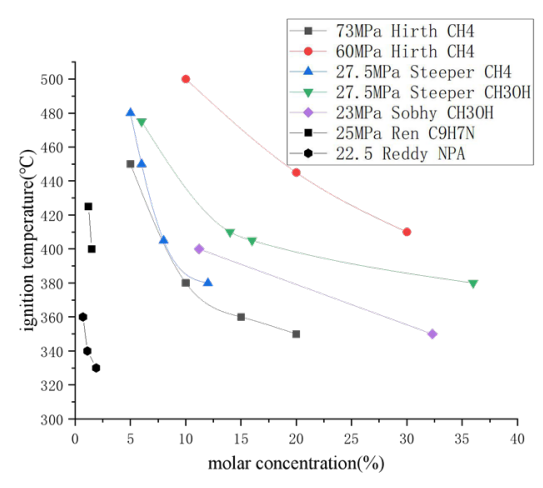

Fig. 4. Relationship between ignition temperature and fuel concentration (semi-batch reactor and batch reactor)

Other scholars have done experiments on the ignition characteristics of continuous reactors. As shown in Figure 5, experiments by Narayanan[22] who used WCHB-3 showed that the ignition temperature of $7.1 \mathrm{~mol} \%$ methanol was $452{ }^{\circ} \mathrm{C}$ under the condition of 25 $\mathrm{MPa}$ and pure oxygen as the oxidant. The experiment by Weber[23] who used WCHB showed that under the condition of $25 \mathrm{MPa}$ and pure oxygen as the oxidant, ignition temperature of $10 \mathrm{~mol} \%$ methanol was $520{ }^{\circ} \mathrm{C}$. Experiments conducted by the WCHB of Prikopsky[11] showed that $9.7 \mathrm{~mol} \%$ of methanol had an ignition temperature of $410^{\circ} \mathrm{C}$ to $430^{\circ} \mathrm{C}$ when pure oxygen was used as the oxidant. Wellig[10] used the TWR to test the ignition temperature of methanol. Under the condition of $25 \mathrm{MPa}$, while the oxidant was pure oxygen, the methanol concentration was increased from $9.7 \mathrm{~mol} \%$ to $12.3 \mathrm{~mol} \%$, and the ignition temperature is decreased from $490{ }^{\circ} \mathrm{C}$ to $460{ }^{\circ} \mathrm{C}$. Zhang[5] used the TWR to measure the ignition temperature of methanol. The oxidant used was oxygen. At $23 \mathrm{MPa}$, the ignition temperature of methanol at $4.2 \mathrm{~mol} \%$ was $600{ }^{\circ} \mathrm{C}$, and the ignition temperature decreased to $460{ }^{\circ} \mathrm{C}$ at $7.0 \mathrm{~mol} \%$. Bermejo[14] conducted supercritical hydrothermal combustion experiments in a tubular reactor showed that $1.2 \mathrm{~mol} \%$ of isopropanol had an ignition temperature of $450^{\circ} \mathrm{C}$ when air was used as the oxidant. Serikawa[24] conducted experiments with supercritical hydrothermal combustion in a pilot scale continuous reactor showed that at $25 \mathrm{MPa}$, air as an oxidant, $2 \mathrm{~mol} \%$ of isopropanol had an igniting temperature of $470{ }^{\circ} \mathrm{C}$. Wellig[13] experimental results on the TWR showed that $9.7 \mathrm{~mol} \%$ methanol ignition temperature was $472-490^{\circ} \mathrm{C}$, pure oxygen as an oxidant.

It can be seen that a lower IPA concentration can ignite at $450^{\circ} \mathrm{C}$ comparing with methanol and the ignition temperature of the WCHB and that of the TWR have no obvious boundaries. In fact, because of the experimental conditions and equipment differences between experiments conducted by various scholars, it is not meaningful to uniformly compare the ignition temperature. In addition, different injection flow rates will also affect the ignition temperature. 


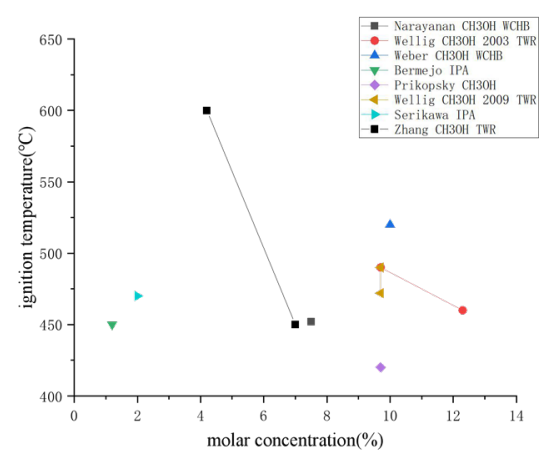

Fig. 5. Relationship between ignition temperature and fuel concentration (continuous reactor)

\subsection{Extinction temperature}

The extinction temperature in supercritical hydrothermal combustion means the minimum injection temperature of the fuel capable of maintaining hydrothermal flame when a hydrothermal flame has already been generated in the reactor. Scholars often study ignition characteristics and extinction characteristics simultaneously in experiments. The study of extinction temperature can only be carried out in the continuous reactor. As shown in Figure 6, the experimental results of Wellig's TWR[10] show that under the condition of $25 \mathrm{MPa}$ and pure oxygen as the oxidant, $7.1 \mathrm{~mol} \%$ of the methanol extinction temperature was $373{ }^{\circ} \mathrm{C}$, and when the methanol concentration increased to $17.2 \mathrm{~mol} \%$, the extinction temperature decreased to $100^{\circ} \mathrm{C}$. Another set of experiments by Wellig[13] showed that when the methanol concentration under the same conditions increased from $3.5 \mathrm{~mol} \%$ to $20.2 \mathrm{~mol} \%$, the extinction temperature decreased from $444{ }^{\circ} \mathrm{C}$ to $25{ }^{\circ} \mathrm{C}$, and the fuel can be injected at ambient temperature to keep the hydrothermal flame from extinguishing. The supercritical hydrothermal combustion experiment of WCHB of Weber[25] shows that under $25 \mathrm{MPa}$, pure oxygen is used as oxidant, when the methanol concentration increased from $2.3 \mathrm{~mol} \%$ to $15.8 \mathrm{~mol} \%$, and the extinction temperature decreased from $550^{\circ} \mathrm{C}$ to $100^{\circ} \mathrm{C}$. Zhang's TWR[5] measured that under $23 \mathrm{MPa}$ with pure oxygen as oxidant, methanol concentration increased from $4.2 \mathrm{~mol} \%$ to $7 \mathrm{~mol} \%$, and the extinction temperature decreased from $405^{\circ} \mathrm{C}$ to $301^{\circ} \mathrm{C}$. It can be seen that under the same conditions, the extinction temperature decreases as the fuel concentration increases, and the temperature can drop to ambient temperature. The form of the reactor (TWR and WCHB) has little effect on the extinction temperature. 


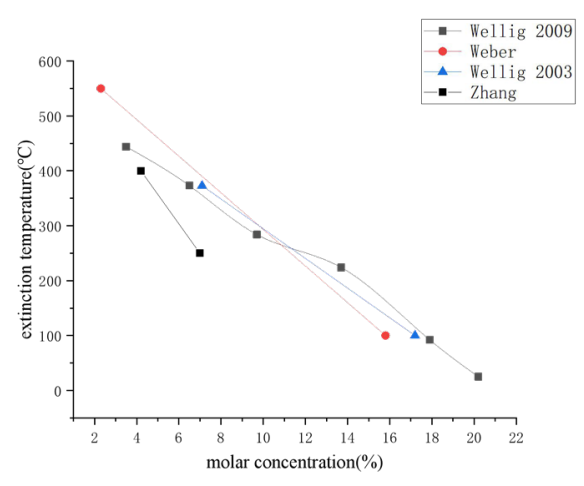

Fig. 6. Relationship between extinction temperature and fuel concentration

\subsection{Other flame characteristics}

In addition to studying the ignition characteristics and extinction characteristics, scholars have also studied other flame Characteristics, such as the flame height and the luminance. The intermittent experimental study by Schilling[2] shows that the increase of pressure will increase the flame height. Under the condition of pure oxygen as oxidant and $30 \mathrm{~mol} \%$ methane as fuel, the flame height will increase from $1.2 \mathrm{~mm}$ at $30 \mathrm{MPa}$ to $3.7 \mathrm{~mm}$ at 200 $\mathrm{MPa}$, and the diameter is kept constant at $0.5 \mathrm{~mm}$. The experiment done by Pohsner[26] under similar conditions with Schilling shows that at $97 \mathrm{MPa}$, the flame height is $2 \mathrm{~mm}$ and the diameter is $0.7 \mathrm{~mm}$. He estimated that flame height was related to the nozzle diameter and pressure of the reactor. Serikawa[24] used a pilot scale continuous reactor to carry out hydrothermal combustion experiments of isopropanol. It was found that at $25 \mathrm{MPa}, 6 \mathrm{~mol} \%$ of isopropanol showed a light blue color at a 1.1 times oxidation coefficient, and the maximum temperature was $830^{\circ} \mathrm{C}$, while at 2.2 times the oxidation coefficient, the flame is red and the maximum temperature rises to $1100^{\circ} \mathrm{C}$.

\subsection{Destruction efficiency}

Scholars also studied the destruction efficiency of organic matter in a supercritical hydrothermal combustion environment. For methanol and methane, Roche[27] found that removal rate in WCHB was between $80 \%$ and $96 \%$, while the residence time was $20 \mathrm{~ms}$ $50 \mathrm{~ms}$, and the flame temperature was $900-1100{ }^{\circ} \mathrm{C}$. Wellig[10] found that the removal rate of methanol in TWR exceeded $99.8 \%$, and the residence time was $50 \mathrm{~ms}-100 \mathrm{~ms}$. Príkopský[11] found that the removal rate of methanol in the third generation TWR is $97.85 \%-99.99 \%$. For isopropanol, Bermejo[14] found that at $450-500{ }^{\circ} \mathrm{C}$, as the residence time was less than $0.4 \mathrm{~s}$ in continuous reactor, the hydrothermal flame ignited and the TOC removal rate was more than $99 \%$. Sato[28] found that the removal rate of isopropanol in continuous reactor at $25 \mathrm{MPa}$ reached 99.98\%. Serikawa[24] of Japan conducted a hydrothermal combustion experiment of dioxins and hexanes with a continuous reactor of pilot plant under conditions of $25 \mathrm{MPa}$ and air as the oxidant. Experimental result shows that the removal rate of dioxins is higher than $99.9 \%$. Sobhy[9] used a semi-batch reactor at $25 \mathrm{MPa}$ and the oxidant was air for hydrothermal combustion experiments, and found that the conversion of naphthalene and methanol was as high as $99.9 \%$. Cabeza[29] used a tubular reactor to carry out hydrothermal combustion experiments to destroy acetic acid and ammonia respectively and isopropanol was used as fuel. It was found that the TOC removal 
rate of acetic acid and isopropanol was as high as $99 \%$ at temperatures above $750{ }^{\circ} \mathrm{C}$, and the TOC removal rate of ammonia and isopropanol reached $99 \%$, but the maximum TN removal of ammonia was never higher than $92 \%$. In another experiment, Cabeza[15] used the WCHB for hydrothermal combustion experiments to destroy ammonia, while the temperature was higher than $600{ }^{\circ} \mathrm{C}$ and isopropanol was used as an auxiliary fuel. It was found that the TOC removal rate was up to $99.99 \%$, and the conversion rate of ammonia nitrogen is higher than $99.9 \%$. If the supercritical hydrothermal combustion experiment of sludge is carried out with isopropanol as an auxiliary fuel, the TOC removal rate is as high as $99.5 \%$. It can be seen that under the condition of supercritical hydrothermal combustion, the removal rate of refractory organic matter is extremely gratifying.

Table 1. Removal rate of organic matter under supercritical hydrothermal combustion conditions.

\begin{tabular}{|c|c|c|c|c|}
\hline Author & Source & $\begin{array}{l}\text { Types of } \\
\text { reactor }\end{array}$ & $\begin{array}{c}\text { Organic } \\
\text { matter }\end{array}$ & Removal rate \\
\hline Roche & [27] & WCHB & $\begin{array}{l}\text { Methanol and } \\
\text { methane }\end{array}$ & $80 \%-96 \%$ \\
\hline Wellig & [10] & TWR & Methanol & $>99.8 \%$ \\
\hline Príkopský & [11] & TWR & Methanol & $\begin{array}{l}97.85 \%- \\
99.99 \% \\
\end{array}$ \\
\hline Bermejo & [14] & $\begin{array}{l}\text { Tubular } \\
\text { reactor }\end{array}$ & Isopropanol & $>99 \%$ \\
\hline Sato & [28] & $\begin{array}{l}\text { Tubular } \\
\text { reactor }\end{array}$ & Isopropanol & $99.98 \%$ \\
\hline Serikawa & [24] & $\begin{array}{l}\text { Tubular } \\
\text { reactor }\end{array}$ & $\begin{array}{c}\text { Dioxins and } \\
\text { hexanes }\end{array}$ & $>99.9 \%$ \\
\hline Sobhy & [9] & $\begin{array}{l}\text { Semi-batch } \\
\text { reactor }\end{array}$ & $\begin{array}{l}\text { Naphthalene } \\
\text { and methanol }\end{array}$ & $99.90 \%$ \\
\hline \multirow[t]{2}{*}{ Cabeza } & \multirow[t]{2}{*}{ [29] } & \multirow{2}{*}{$\begin{array}{l}\text { Tubular } \\
\text { reactor }\end{array}$} & $\begin{array}{l}\text { Acetic acid } \\
\text { and } \\
\text { isopropanol }\end{array}$ & $99 \%$ \\
\hline & & & $\begin{array}{l}\text { Ammonia and } \\
\text { isopropanol }\end{array}$ & $99 \%$ \\
\hline \multirow{2}{*}{ Cabeza } & \multirow{2}{*}{ [15] } & \multirow{2}{*}{ WCHB } & $\begin{array}{l}\text { Isopropanol } \\
\text { and ammonia }\end{array}$ & $99.99 \%$ \\
\hline & & & $\begin{array}{l}\text { Isopropanol } \\
\text { and sludge }\end{array}$ & $99.50 \%$ \\
\hline
\end{tabular}

It can be seen from table 1 that under the conditions of supercritical hydrothermal combustion, the removal rate of most organic matters is above $99 \%$ regardless of the reactor. The refractory organics can be ignited by mixing with the fuel to increase the removal rate.

\section{Conclusion and outlook}

The continuous reactor designed in each organization is very sophisticated, which can avoid the two major problems of reaction in the supercritical state: salt precipitation and corrosion. The ignition temperature decreases as the pressure increases and the fuel concentration increases. The extinction temperature decreases as the fuel concentration increases. The increase in pressure will result in the increase in the height of the flame. The increase in the oxidation coefficient results in the increase in flame temperature and the change in flame colour. The removal rate of different organic matters was also summarized under supercritical hydrothermal combustion, and the removal rate of more than $99 \%$ was basically achieved. 
Although the TWR and WCHB designed by various organizations are able to avoid the two major problems in SCWO, the industrial applications now just use tubular reactors which cannot avoid the problems mentioned earlier. How to promote the TWR and WCHB into industrial applications should be the focus of future study.

The supercritical hydrothermal combustion experiments carried out by most scholars are using alcohol fuels, and the advantages of supercritical hydrothermal combustion removing refractory organic matters are not demonstrated. The interaction between the refractory organic matter and fuel in supercritical hydrothermal combustion is also the focus of future study.

\section{Acknowledgement}

This research is supported by the Fundamental Research Funds for the Central Universities [xjj2018201] and [xjj2018006], the Projects from National Natural Science Foundation of China [51871179].

\section{References}

1. E.U. Franck, Fluids at high pressures and temperatures. J. Chem. Thermodyn. 19, 225242, (1987)

2. W. Schilling, E.U. Franck, Combustion and Diffusion Flames At High Pressures To 2000 Bar. Physical Chem. Chem. Phys. 92, 631-636, (1988)

3. M. Modell, Supercritical Water: Testing Reveals New Process Holds Promise. Solid Waste Manag. 25, 26-28,30,76, (1982)

4. H. Ma, Fundamental Research on Power-Generating System Coupling of Gasification and Hydrothermal Combustion of Coal in Supercritical Water. Xi'an Jiaotong University .(2013)

5. F. Zhang, Y. Zhang, C. Xu, S. Chen, G. Chen, C. Ma, Experimental Study on the Ignition and Extinction Characteristics of the Hydrothermal Flame. Chem. Eng. Technol. 38, 2054-2066, (2015)

6. C. Augustine, J.W. Tester, Hydrothermal flames: From phenomenological experimental demonstrations to quantitative understanding. J. Supercrit. Fluids. 47, 415-430, (2009)

7. S.N. Reddy, S. Nanda, U.G. Hegde, M.C. Hicks, J.A. Kozinski, Ignition of hydrothermal flames. RSC Adv. 5, 36404-36422, (2015)

8. R.R. Steeper, S.F. Rice, M.S. Brown, S.C. Johnston, Methane and methanol diffusion flames in supercritical water. J. Supercrit. Fluids. 5, 262-268, (1992)

9. A. Sobhy, I.S. Butler, J.A. Kozinski,. Selected profiles of high-pressure methanol-air flames in supercritical water. Proc. Combust. Inst. 31 II, 3369-3376, (2007)

10. B. Wellig, Transpiring wall reactor for supercritical water oxidation. Swiss Federal Institute of Technology Zurich. (2003)

11. K. Príkopský, Characterization of continuous diffusion flames in supercritical water. Swiss Federal Institute of Technology Zurich. (2007)

12. T. Meier, P. Stathopoulos, P. Rudolf von Rohr, Hot surface ignition of oxygen-ethanol hydrothermal flames. J. Supercrit. Fluids. 107, 462-468, (2016) 
13. B. Wellig, M. Weber, K. Lieball, K. Príkopský, P. Rudolf von Rohr, Hydrothermal methanol diffusion flame as internal heat source in a SCWO reactor. J. Supercrit. Fluids. 49, 59-70, (2009)

14. M.D. Bermejo, P. Cabeza, M. Bahr, R. Fernández, V. Ríos, C. Jiménez, M.J. Cocero, Experimental study of hydrothermal flames initiation using different static mixer configurations. J. Supercrit. Fluids. 50, 240-249, (2009)

15. P. Cabeza, J.P. Queiroz, S. Arca, C. Jiménez, A. Gutiérrez, M.D. Bermejo, M.J. Cocero, Sludge destruction by means of a hydrothermal flame. Optimization of ammonia destruction conditions. Chem. Eng. J. 232, 1-9, (2013)

16. M.D. Bermejo, P. Cabeza, J.P.S. Queiroz, C. Jiménez, M.J. Cocero, Analysis of the scale up of a transpiring wall reactor with a hydrothermal flame as a heat source for the supercritical water oxidation. J. Supercrit. Fluids. 56, 21-32, (2011)

17. Y. Li, S. Wang, M. Ren, J. Zhang, D. Xu, L. Qian, P. Sun, Recent advances on research and application on supercritical hydrothermal combustion technology. Chem. Ind. Eng. Prog. 35, 1942-1955, (2016)

18. J.U. Steinle, E.U. Franck, High-Pressure Combustion - Ignition Temperatures To 1000 Bar. Berichte Der Bunsen-Gesellschaft-Physical Chem. Chem. Phys. 99, 66-73. (1995)

19. T. Hirth, E.U. Franck, Oxidation and Hydrothermolysis of Hydrocarbons in Supercritical Water at High Pressures. Berichte der Bunsengesellschaft für Phys. Chemie. 97, 1091-1097, (1993)

20. S.N. Reddy, S. Nanda, U.G. Hegde, M.C. Hicks, J.A. Kozinski, Ignition of n-propanolair hydrothermal flames during supercritical water oxidation. Proc. Combust. Inst. 36, 2503-2511, (2017)

21. M. Ren, S. Wang, C. Yang, H. Xu, Y. Guo, D. Roekaerts, Supercritical water oxidation of quinoline with moderate preheat temperature and initial concentration. Fuel. 236, 1408-1414, (2019)

22. C. Narayanan, C. Frouzakis, K. Boulouchos, K. Príkopský, B. Wellig, P. Rudolf von Rohr, Numerical modelling of a supercritical water oxidation reactor containing a hydrothermal flame. J. Supercrit. Fluids. 46, 149-155,(2008)

23. M. Weber, Apparate einer SCWO-Anlage und deren Leistungsfähigkeit. Swiss Federal Institute of Technology Zurich. (1997)

24. R.M. Serikawa, T. Usui, T. Nishimura, H. Sato, S. Hamada, H. Sekino, Hydrothermal flames in supercritical water oxidation: Investigation in a pilot scale continuous reactor. Fuel. 81, 1147-1159, (2002)

25. M. Weber, C. Trepp, Required fuel contents for sewage disposal by means of supercritical wet oxidation (SCWO) in a pilot plant containing a wall cooled hydrothermal burner (WCHB). Process Technol. Proc. 12, 565-574, (1996)

26. G.M. Pohsner, E.U. Franck, Spectra and temperatures of diffusion flames at high pressures to 1000 bar. Physical Chem. Chem. Phys. 98, 1082-1090, (1994)

27. H.L. Roche, Wandgekühlter Hydrothermal-Brenner (WHB) für die überkritische Nassoxidation. Swiss Federal Institute of Technology Zurich. (1996)

28. H. Sato, S. Hamada, R.M. Serikawa, T. Nishimura, T. Usui, H. Sekino, Continuous flame oxidation in supercritical water. High Press. Res. 20, 403-413, (2001)

29. P. Cabeza, M.D. Bermejo, C. Jiménez, M.J. Cocero, Experimental study of the supercritical water oxidation of recalcitrant compounds under hydrothermal flames using tubular reactors. Water Res. 45, 2485-2495, (2011) 